\title{
SOBRE CORPORALIDADE E ESCOLARIZAÇÃO: CONTRIBUIÇÕES PARA A REORIENTAÇÃO DAS PRÁTICAS ESCOLARES DA DISCIPLINA DE EDUCAÇÃO FÍSICA
}

\author{
Marcus Aurélio Taborda de Oliveira \\ Professor do Programa de Pós-Graduação em Educação/Universidade Federal do Paraná e pesquisador CNPq
}

Luciane Paiva Alves de Oliveira

Professora do Setor de Educação da Universidade Federal do Paraná

Alexandre Fernandez Vaz

Professor da Universidade Federal de Santa Catarina e pesquisador CNPq

\begin{abstract}
Resumo
O presente texto reúne contribuições para o debate sobre a constituição de diretrizes curriculares para o ensino de Educação Física no estado do Paraná. Depois de apresentar o contexto no qual foi gerado - que inclui resultados de debates com professores escolares daquele estado - discute-se uma concepção para a disciplina Educação Física na escola, espaço pedagógico no qual a educação do corpo é protagonista. Dessa forma, é apresentada uma série de conceitos e argumentos em favor da corporalidade como centro articulador das aulas de Educação Física que, por sua vez, podem se organizar em torno de quatro eixos: o corpo que brinca e aprende, potencial expressivo do corpo, desenvolvimento corporal e construção da saúde, relação do corpo com o mundo do trabalho. Argumenta-se, em consonância com o conceito de corporalidade apresentado, por um alargamento da compreensão das práticas corporais que considere elementos para além do movimento corporal.
\end{abstract}

Palavras-chave: corporalidade - educação do corpo - Educação Física Escolar - Diretrizes Curriculares - Paraná.

\section{Introdução: o contexto da propositura}

$\mathrm{O}$ contexto do qual surgiu o presente trabalho pode ser apreendido em uma perspectiva pluridimensional. De pronto, é preciso destacar que os autores vem há algum tempo refletindo, por vias nem sempre as mesmas, sobre uma chamada educação do corpo nos ambientes escolares. Ainda que não se restrinja à esfera da Educação Física como disciplina escolar, essa reflexão não tem deixado fora seu espaço específico. No entanto, temos nos pautado por um pensamento que se propõe crítico a muitas das formas que essa disciplina vem assumindo na escola brasileira. Inclinamo-nos a pensar que muito dessa herança ganha materialidade nas práticas escolares de Educação Física. Esse foi o nosso ponto de partida.

Uma outra dimensão que motivou a construção deste texto foi a possibilidade aberta pela Secretaria de Estado da Educação do Paraná, com relação à construção das Diretrizes Curriculares para o Ensino de Educação Física no Ensino Fundamental. Em um trabalho iniciado no final do segundo semestre de 2003, para o qual foi convidado o professor Marcus Aurélio Taborda de Oliveira, junto à equipe responsável pela Educação Física na Coordenação de Ensino Fundamental daquela secretaria, desenvolveu-se o entendimento de que a reforma curricular no âmbito do estado deveria levar em consideração (1) a experiência docente, (2) a diversidade cultural do estado e (3) uma perspectiva de Educação Física que considerasse o corpo e suas manifestações em perspectiva histórico-cultural.

Nos anos de 2004 e 2005, de formas distintas participamos da elaboração das Diretrizes Curriculares do Estado, convidados que fomos pela gestão à frente daquela secretaria. 
De início, a partir das contribuições de Luciane Paiva Alves de Oliveira e de Marcus Aurélio Taborda de Oliveira (2004), foi produzido um texto de trabalho intitulado Corporalidade e cultura escolar: refletindo sobre a reorientação das práticas escolares de Educação Física no Estado do Paraná, o qual subsidiou os debates no I Seminário Estadual das Diretrizes Curriculares para o Ensino de Educação Física, realizado em maio de 2004, em Curitiba. Os resultados de três dias de trabalho foram sintetizados em um relatório, o qual viria subsidiar o II Seminário, realizado em setembro, em Foz do Iguaçu. Naquela cidade, mais três dias de trabalhos de aprofundamento dos textos propostos e das perspectivas dos docentes, permitiram desenvolver a compreensão que a proposta de construção das diretrizes, pautada na noção de corporalidade, ganhava densidade. Deste segundo seminário, sob a responsabilidade também de Luciane Paiva Alves de Oliveira e de Marcus Aurélio Taborda de Oliveira, e com a participação de Tarcísio Mauro Vago, surgiu um documento preliminar, que viria a ser analisado e debatido pelos docentes dos diferentes NREs (Núcleos Regionais de Ensino) do Paraná ${ }^{1}$. Ao final do primeiro semestre de 2005, mais uma oportunidade de encontro com os professores paranaenses se deu em Faxinal do Céu, desta feita sob a responsabilidade do professor Alexandre Fernandez $\operatorname{Vaz}^{\mathrm{a} *}$.

$\mathrm{O}$ que pretendemos, pois, com essa publicação - resultado de nossa contribuição a esse processo -, é submeter ao escrutínio da comunidade dos professores e pesquisadores de Educação Física, uma proposta que pretende explorar na disciplina Educação Física todo o seu potencial em um projeto de forma̧̧ão humana, no qual a escola tem lugar destacado. No mesmo movimento, reconhecemos os professores e as professoras escolares como

1 Do conjunto da contribuição dos docentes e do refinamento conceitual da proposta surgiu a necessidade de produção de um outro texto-base, o qual trata das relações entre trabalho, técnica e corporalidade (OLIVEIRA; TABORDA DE OLIVEIRA, 2005). intelectuais responsáveis pela crítica das formas historicamente prevalecentes de educação do corpo, o que significa tomá-los (as) como os(as) agentes mais qualificados para pensar, no âmbito escolar, formas alternativas de construção de novas "maneiras de fazer" a Educação Física escolar. Assim, cultura escolar, corporalidade e experiência são noções essenciais nesse nosso intento.

Esperamos, portanto, que essa contribuição ao processo de construção das Diretrizes Curriculares de Educação Física para o ensino fundamental no Estado do Paraná - escrita para e no o diálogo com os pares, inclusive e principalmente aqueles que são professores escolares - seja uma baliza para o debate daquilo que pode ser feito na Educação Física escolar, a partir de uma propositura que não pretende baratear o lugar da Educação Física na escola. Antes, radicalizando no pensamento sobre as práticas, movimento que se deu principalmente no debate de experiências de cerca de trezentos professores escolares presentes nos seminários, entendemos que essa disciplina sintetiza o legado iluminista/moderno que, por um lado, reduz o corpo e as suas expressões à condição de mera natureza manipulável, mas, por outro, confere-lhe lugar destacado na afirmação da sociedade e do indivíduo. Processo inconcluso, certamente, permite que busquemos formular um projeto a partir da crítica radical daquele outro que, de alguma maneira, somos nós: as práticas escolares de Educação Física.

\section{Concepção de educação física}

A iniciativa de reformulação das diretrizes curriculares para o ensino de Educação Física na escola fundamental obedece a vários imperativos. Não devemos esquecer, em um primeiro plano, das próprias políticas públicas para a educação, em consonância com outras políticas públicas de estado. Porém, é possível observar também um outro imperativo, qual seja, um rico movimento nascido da própria 
experiência dos professores escolares, da sua própria prática cotidiana. Esse movimento significa uma reflexão dos docentes sobre a insuficiência do modelo atual de ensino, o qual muitas vezes privilegia o fenômeno esportivo que, por sua vez, contempla parcialmente a enorme riqueza das manifestações corporais culturalmente produzidas. Essa tendência pode ser percebida em duas dimensões que se complementam. A primeira refere-se a vários tipos de situações identificadas no dia-a-dia de muitas aulas de Educação Física, tais como a auto-exclusão, a falta de interesse de muitos alunos (pelos mais variados motivos), o pouco sentido que a comunidade escolar via de regra vê nessas aulas, a dificuldade dos professores escolares ampliarem o âmbito de sua intervenção na formação das crianças, jovens e adultos, tanto pela falta de políticas de formação continuada, quanto pela insuficiência de interesse pessoal de cada docente, falta de estrutura física e/ou material etc ${ }^{2}$. A partir disso, é preciso reconhecer uma segunda dimensão. Esta se refere a um esforço de uma parte significativa dos professores de Educação Física de enriquecer o escopo da sua intervenção por meio da ampliação do centro de interesses dessa disciplina, movimento que faz deslocar de uma perspectiva naturaliza$d a$, baseada apenas na dimensão motriz, para uma outra, que the reconhece o estatuto cultural, baseada na corporalidade. Portanto, de uma tradição fortemente marcada quase que somente por uma visão limitada das Ciências da Natureza, a Educação Física tem avançado para preocupações pautadas por disciplinas variadas que permitem o entendimento do corpo em muito de sua complexidade ${ }^{3}$.

2 É necessário reconhecer que essas situações não podem ser generalizadas. Porém, é possível observar que elas ocorrem em algumas comunidades, com maior ou menor intensidade. Portanto, trata-se de um problema relevante que os professores de Educação Física devem considerar a fim de reorientar a sua ação docente.

3 Um exemplo dessa mobilização pode ser observado na riqueza dos relatos dos professores participantes dos en-
Pensar, pois, quaisquer mudanças no plano curricular, implica a necessidade de olharmos detidamente para a experiência docente, manifestada de formas diversas em lugares diferentes. Um dos desafios é procurar articular satisfatoriamente a pluralidade de experiências de ensino oriundas do dia-a-dia do professor, condição básica do sucesso de qualquer proposta de reforma curricular. Nessa direção é preciso reconhecer, então, as necessidades de distintos contextos comunitários que, uma vez articulados ao contexto societário mais amplo, vêem atualizarem-se diferentes formas históricas de dominação. A escola precisa estar atenta à atualização das demandas sócioculturais, uma vez que entre as suas finalidades maiores inscreve-se, além da produção e socialização do conhecimento, justamente a crítica das formas de organização da cultura. Assim, ao contemplar pela via da escolarização as marcas das manifestações corporais no processo de formação humana, a Educação Física escolar tem-se inserido no plano de uma reflexão sobre diferentes problemáticas sociais, algumas de há muito objeto de preocupação dos educadores, outras que surgem conforme se transforma a própria organização social. Entre esses elementos ganham destaque: a violência; os preconceitos étnicos, de sexo, de classe, entre outros; as formas corporais de exclusão social; as potencialidades e os limites das práticas corporais como possibilidade de formação; a ênfase sobre uma estética corporal que se orienta por padrões estereotipados, resultados de uma exacerbação atual do corpo como "lugar" da felicidade; o exercício da dominação na prostituição de crianças e jovens, no tráfico e no consumo de drogas, no trabalho infantil e escravo, na negação do acesso aos bens culturais etc. Todos esses elementos, de forma direta ou indireta, ins-

contros descentralizados para a formulação das Diretrizes Curriculares Estaduais, bem como nas propostas formuladas para o Portal da Educação, da Secretaria de Estado da Educação, e no resultado impressionante e estimulante de muitos dos trabalhos ali desenvolvidos. 
crevem-se na corporalidade, entendida como a expressão criativa e consciente do conjunto das manifestações corporais historicamente produzidas, as quais pretendem possibilitar a comunicação e a interação de diferentes indivíduos com eles mesmos, com os outros, com o seu meio social e natural. Essas manifestações baseiam-se no diálogo entre diferentes indivíduos, em um contexto social organizado em torno das relações de poder, linguagem e trabalho ${ }^{4}$. Nessa direção, o objetivo último das práticas corporais escolares em geral, e da Educação Física em particular, deve ser a humanização das relações sociais. Portanto, a noção de corporalidade permite ampliar as possibilidades de intervenção educacional do professor de Educação Física, superando a dimensão meramente motriz da sua aula sem, no entanto, negar o movimento como possibilidade de expressão humana. Atentos ao que foi anteriormente caracterizado como experiência dos professores, seus interesses, suas expectativas e necessidades, articulados com as finalidades que regem o ensino escolar e aos resultados esperados do processo de escolarização, propomos uma concepção que procure contemplar a complexidade das manifestações corporais humanas e a sua potencialidade formativa.

4 Para Taborda de Oliveira (1998, p. 126) “(...) o profissional de Educação Física precisa compreender-se como aquele intelectual responsável pela organização e sistematização competente e crítica das práticas corporais conscientes do homem e suas determinações pelas relações com o traba1ho, a linguagem e o poder, elementos estruturantes de uma sociedade cindida em classes e, conseqüentemente, em interesses antagônicos. O trabalho, no sentido de transformação da condição natural do homem, produzindo, este, a sua história própria. Porém, essa produção da história (cultura) não se dá sem um substrato ideológico que determina as formas de linguagem. A conformação dos signos sociais (palavra, gesto etc) se dá sempre num contexto de relações sociais e orientações ideológicas [...]. Finalmente, as relações de poder, também orientadas pelo jogo de forças determinado ideologicamente pela própria cultura, que cristaliza a condição dos sujeitos em determinada estrutura social. Pensar a Educação Física no interior da escola sem pensar os seus determinantes culturais é, como a sua história bem tem demonstrado, torná-la acéfala."
Ao observar as contribuições dos professores em todas as etapas do processo de formulação das DCEs para a Educação Física, fomos provocados a enxergar a identificação que eles estabelecem entre a noção de corporalidade e o seu fazer cotidiano. Aquelas contribuições destacam que, apesar de ainda não terem tido a oportunidade de refletir sobre esse conceito, a concepção de corporalidade já orienta o trabalho de muitos em diferentes contextos e/ou culturas escolares. Não obstante, reconhecem que, no plano das ações que imperam tanto nas aulas de Educação Física como na escola em geral, ainda é necessário superar uma visão fragmentada tanto do ser humano como da cultura. Muitos professores apontam o fato de que esse ainda é um aspecto marcante da cultura escolar e como exemplo indicam que na escola algumas disciplinas são concebidas como responsáveis por "educar o corpo" e outras por "educar a mente", sendo esse um dos obstáculos para uma educação que contemple a corporalidade como elemento central no processo formativo. Ainda no âmbito específico da Educação Física, propõem a necessidade de superar uma visão reducionista que compreende o ser humano como um conjunto de ossos, músculos e nervos, elegendo o movimento corporal - talvez devêssemos dizer deslocamento corporal - como fim único e último de ensino, como se fosse possível um processo formativo de modo fracionado ou esquadrinhado. Apontam que é preciso que estejamos atentos ao fato de que, muitas vezes, a cultura escolar restringe o entendimento da educação do corpo à realização de movimentos mecânicos e repetitivos, reduzindo as aulas de Educação Física à atividade catártica ou meramente complementar a outras disciplinas. Destacamos que as aulas de Educação Física não podem ser um apêndice das demais disciplinas e atividades escolares, nem devem ser um momento subordinado e compensatório para as durezas das aulas em sala. A Educação Física é parte do projeto geral de escolarização e, como tal, tem que estar submetida ao Projeto Político Pedagógico da 
escola. Se a atuação do professor é na quadra e em outros lugares do ambiente escolar, seu compromisso é com a escola, com o projeto de escolarização ali instituído, sempre em favor da formação humana. No entanto, como muitos professores reconhecem, a educação do corpo não se dá apenas nas aulas de Educação Física, mas nas diferentes experiências formativas (ou não-formativas), indo além da vida escolar e se refletindo em toda a vida social dos sujeitos.

Como a literatura aponta, e os professores reconhecem no seu dia a dia, o corpo surge como uma das dimensões humanas que mais recebem atenção no seio de nossa cultura, do ponto de vista estético, tecnológico, científico, profilático etc. Isso, por sua vez, traz uma série de conseqüências para aquilo que compõe nosso entendimento sobre o que é corpo ou o que significa ser corpo no mundo atual. Portanto, faz-se necessário compreender os diferentes saberes, valores, sentimentos e crenças que interferem sobre a constituição de nosso corpo, tanto no plano individual como no social. E, ao longo do processo formativo, torna-se essencial abordar questões como orientação sexual, ética, consumo, trabalho, saúde, violência doméstica, exclusão, preconceitos etc. $\mathrm{O}$ relato de muitos professores que participaram dos debates sobre estas diretrizes reportam que esses aspectos já são tratados nas aulas de Educação Física, todavia indicam que ainda falta uma maior sistematização em relação a essas ações e temas, de tal modo que seja possível sair da provisoriedade que, muitas vezes, orienta seu trabalho, com vistas a realizar algo com maior consistência, efetividade e permanência educacional. Assim é essencial identificar e ampliar essas práticas educativas de maneira organizada e fundamentada, partindo do entendimento de que qualquer iniciativa educacional sobre a corporalidade pauta-se sempre por certa intencionalidade. No entanto, os professores reconhecem que esse intento não se concretizará de forma simples ou fácil. Daí a importância que o conhecimento assume como sus- tentáculo dessa iniciativa de ressignificação da Educação Física na escola. A experiência do professor e o aprofundamento do conhecimento que detêm são peças fundamentais na formulação dessas diretrizes.

Tendo em vista que diferentes culturas escolares podem produzir distintas expectativas e possibilidades, trata-se então de relacionar o que é específico de cada comunidade (núcleo, cidade, bairro, escola) com a produção cultural humana dotada de alguma universalidade. Se lembrarmos que a luta contra as formas de dominação e pela emancipação é condicionante de uma vida mais digna, podemos entender como diferentes culturas escolares podem articular o geral e o particular, preservando a premissa da luta por um mundo onde as oportunidades sejam oferecidas a todos e da mesma forma compartilhadas, tendo como pressuposto o acesso ao conhecimento. Isso, no entanto, sem perder de vista aquilo o que caracteriza cada comunidade na sua singularidade, na possibilidade de comunicar a outras comunidades experiências diferençadas. Portanto, a articulação entre diferentes culturas escolares e o contexto societário mais amplo deve permitir o enriquecimento das formas de atuação dos professores escolares. Conseqüentemente, deve oportunizar uma maior valorização da cultura como lugar de produção de sentido e de potencialização da riqueza da experiência humana, eminentemente corporal - aspecto fundamental para a Educação Física. A noção de cultura escolar, por sua vez, não supõe, como às vezes se interpreta, que não haja constrangimentos estruturais da ordem da política, da economia ou da cultura mais ampla. Não devemos cair no erro de conceber a escola como um lugar imune às influências externas, o que nos levaria a compreender o trabalho do professor como isento da dimensão crítica, transformando a escola em um "deserto social" (VAGO, 1999) no qual as relações estariam isentas de conflito. Ao contrário, por não ser um lugar neutro, é que precisamos compreender em que medida a escola 
pode afirmar-se como alternativa a toda sorte de controle e conformação cultural unilateral.

Por isso é tão importante a articulação entre cultura escolar e cultura primeira dos alunos - aquilo que eles já trazem como acervo de experiências antes de chegarem à escola, a cultura da sua comunidade. Em um estado de forte acento na diversidade étnica como o Paraná, essa necessidade fala por si mesma. No entanto, ao nos depararmos com essas múltiplas culturas não devemos esquecer de procurar perceber o que as une e o que as diferencia. Se as comunidades do litoral têm um grande papel na preservação de práticas culturais tais como o fandango, o sul do estado conheceu uma forte imigração de povos eslavos e o oeste o influxo da cultura oriunda do Rio Grande do Sul. Ao seguirmos compondo esse quadro, notamos como boa parte do norte foi formada a partir da cultura bandeirante, paulista ou caipira, e então vemos a pluralidade de possibilidades que nos oferece a configuração sócio-geográfica-cultural do nosso estado. Isso sem levarmos em conta a cultura das populações ilhéus, ribeirinhas, dos assentamentos, dos quilombos etc., como bem foi lembrado no decorrer do primeiro seminário para estas diretrizes, realizado em Curitiba. O reconhecimento dessa multiplicidade e riqueza pode dar um grande e novo sentido às práticas escolares de Educação Física no plano das políticas públicas.

Isso posto, e considerando o desenvolvimento histórico da disciplina Educação Física nos seus vários momentos de afirmação, permitimo-nos dizer que contemplar a corporalidade como premissa básica pretende dar ainda maior densidade ao que se convencionou chamar de cultura corporal de movimen$t 0^{5}$. Daí a necessidade de entendermos que as

5 Cultura corporal é uma expressão que procura designar o conjunto dos elementos que se exteriorizam pelo corpo em movimento e configuram uma linguagem. Seriam exemplos os esportes, os jogos, as danças, as lutas, as ginásticas, as acrobacias, entre outros. Ela foi amplamente divulgada no Brasil por meio do livro Metodologia de Ensino de Educação inquietações da prática pedagógica podem ser um momento oportuno de superação de formas anteriores de concepção e atuação junto às escolas públicas. Nesse sentido, a superação é entendida como ir além, não como simples negação do que nos precedeu. Assim, as formas anteriores - algumas já consagradas - de atuação e concepção docentes devem ser objeto de análise, de crítica, de reorientação, quando for o caso. Isso para que se possa refletir sobre sua permanência e/ou transformação.

No entanto, quando olhamos para as tradições já arraigadas da psicomotricidade e da educação esportiva, somos levados a perguntar em que medida temos nos valido do riquíssimo patrimônio cultural vinculado ao corpo e suas expressões, uma vez que ambos podem ter um claro caráter de padronização cultural. No caso da psicomotricidade, o diálogo com os professores aponta que muitos entendem que a perspectiva de desenvolvimento não pode dizer respeito exatamente às "condutas psicomotoras", mas à necessidade de lutarmos - via escola - pela possibilidade de todos terem oportunidades de um desenvolvimento condizente com a dignidade que merece a vida humana. Ou seja, os professores estão conscientes de que pouco adianta trabalharmos condutas motoras se a dignidade não for uma possibilidade para todos aqueles que freqüentam a escola. Entendemos que quando falamos em dignidade já pressupomos que o direito ao brincar, ao jogar, ao aprender, à saúde, à integração social etc., dela faz parte. Nesse sentido, a psicomotricidade tal como se desenvolveu neste e em outros países a partir dos anos 1970, tem pouquíssimo a contribuir para a ressigni-

Fisica, escrito por um Coletivo de Autores (1992). Não é propriamente uma expressão "original", uma vez que já era empregada no contexto dos países socialistas, em especial, na República Democrática Alemã (Körperkultur). Este conceito rivaliza/complementa o de cultura de movimento, que procura deslocar a ênfase para o movimentar-se (Sichbewegen), para os sentidos que o movimento pode ter para seu autor/ator, reconhecendo que o movimentar-se (e não simplesmente "deslocar-se") comporta as dimensões do agir, do pensar e do sentir (TREBELS, 2003; KUNZ, 1991). 
ficação das aulas de Educação Física. Por que isso acontece? Porque a psicomotricidade traz consigo um modelo clínico que é impróprio para a escolarização ao procurar determinar o que seria normal ou anormal sem considerar o contexto histórico, político, social e cultural que oferece balizas para a corporalidade. Além disso, não podemos mais permanecer com uma concepção de infância que seja "etapista", como se todas as crianças fossem iguais e uniformes em suas respectivas idades - supondo, portanto, que aquelas que não se encaixam no modelo seriam "anormais". A complexidade da sociedade contemporânea, ao contrário, nos oferece a possibilidade de conhecer diferentes experiências infantis. As múltiplas formas de organizar a família, a condição étnica, de gênero, migratória, religiosa, entre tantas outras, delimita a infância e suas expressões. Não por acaso é possível hoje falar em infâncias no plural e nas culturas infantis ${ }^{6}$.

A influência do esporte é ainda mais problemática. Isso porque ele é um desses fenômenos que têm concorrido justamente para obscurecer a riqueza de diferentes práticas corporais, graças à massiva determinação dos meios de comunicação e da própria herança da Educação Física brasileira. Assim, quando uniformizamos em torno do esporte as manifestações de diferentes origens, registros e significados, devemos nos perguntar em que medida essa nossa prática escolar tem contribuído para a formação dos nossos alunos. De todos os nossos alunos e não da minoria que freqüenta os jogos escolares ${ }^{7}$. Parece-nos que o

6 Para uma crítica da psicomotricidade e uma explanação mais detalhada sobre a multiplicidade da infância contemporânea, também presente na Educação Física, consultese os trabalhos de Deborah Sayão (entre outros, 2002). A respeito do debate específico sobre as culturas infantil, vale lembrar, entre outros trabalhos, aquele organizado por Faria, Demartini e Prado (2002).

7 É digno de destaque que os jogos escolares expressam um paradoxo: eles supõem, por um lado, que os professores têm de lidar com toda uma pressão por resultados cuja origem está na tradição da área, em suas próprias biografias, na comunidade escolar, em especial nas expectativas de pais, alu- esporte não deve ser negado como patrimônio cultural comum da humanidade. Mas devemos articulá-lo com inúmeras outras possibilidades corporais também constituintes desse mesmo patrimônio. Mais do que isso, tratar o esporte de forma simplista, como comumente o fazemos nas aulas de Educação Física, é negar a grandeza do acervo cultural que ele compõe. $\mathrm{O}$ esporte é um fenômeno da cultura popular de raiz urbana, parte dos processos de constituição da cultura numa sociedade de massas, com todas as implicações que isso traz, e o vínculo da sociedade brasileira com o futebol é apenas um exemplo entre muitos. Precisamos tratar o esporte de forma mais ampla, reconhecendo sua condição técnica, tática, seus elementos básicos, mas também o sentido da competição esportiva, a expressão cultural, social e histórica de suas práticas.

Lembremos que, se o esporte tende a seguir as mesmas regras em qualquer município ou região (diga-se, em qualquer país) as formas de dançar são mais distintivas, tais como são as brincadeiras, as maneiras de se expressar corporalmente, as necessidades de cada comunidade diante das possibilidades da Educação Física escolar. Ou seja, estamos diante de um exemplo claro que nos aparece como um desafio: transmitir a cultura universal, os saberes conhecidos como clássicos, preservando também aquilo que é peculiar em cada região ou comunidade. Desse diálogo entre a cultura considerada universal e aquela chamada de primeira, a escola surge como centro cultural capaz de transmitir, mas também de produzir culturalmente. Daí os professores tecerem largos comentários sobre a necessidade de a Educação Física atualizar-se, atentando para questões referentes ao corpo e à corporalidade que estão expressas na religião, nos preconceitos, nas etnias, na sexualidade, na violência,

nos e diretores. Por outro, não são boas as condições para a preparação dos alunos para as competições. Há ainda um agravante: é possível compatibilizar uma proposta avançada de Educação Física com os modelos que repetem uma educação esportiva bastante questionável? 
na exclusão, no individualismo exacerbado, na competição etc. Trata-se, em última análise da produção de novas sínteses culturais e mesmo de nova cultura.

Parece ser também uma necessidade atual de nós professores refletirmos sobre os limites da motricidade como referência para as aulas de Educação Física, uma vez que o movimento humano é histórica e culturalmente orientado, implica sentido e intencionalidade, conforme indica a noção de corporalidade que vimos trabalhando. Esse movimento, que é corporal e humano, não pode continuar sendo tratado como um dado da natureza, conforme a tradição da área de Educação Física, que ainda perdura em muitos lugares. Ao contrário, o corpo humano que se movimenta também se expressa de outras maneiras que não necessariamente implicam motricidade. Contudo, isso não quer dizer que devamos nos desfazer do movimento. Devemos insistir que o movimento é expressão corporal, portanto humana. Não devemos simplesmente negá-lo, mas podemos incorporá-lo no plano mais amplo da formação humana pela via da corporalidade. Nesse sentido, também a noção de cultura escolar pode ser útil, justamente por permitir compreender por que grupos distintos têm costumes corporais diferentes, por que se vestem de maneiras diferentes, desenvolvem certas brincadeiras, preconceitos, atividades que acabam por distingui-los de outros grupos ou comunidades. Se continuarmos tratando o movimento como algo inato, natural, dado, perderemos de vista toda a riqueza da produção cultural de diferentes formas de manifestação corporal. Trata-se, pois, de superar a tradicional ênfase sobre o movimento mecânico, repetitivo, descontextualizado histórica e culturalmente. Para muitos docentes a noção de corporalidade pode ser um significativo ponto de partida.

O planejamento escolar deve voltar-se para a articulação entre aquilo que é específico de cada escola e comunidade e o que configura o conhecimento universal, patrimônio cultural comum. Nesse sentido, encontramos, por parte de alguns colegas professores escolares, uma crítica à idéia de que se trata de perspectivar diferentes culturas. Para alguns professores, seria o caso, na verdade, de aguçar as contradições sociais e torná-las objeto do conteúdo escolar. Parece-nos que a noção de corporalidade expressa justamente essa necessidade: em uma sociedade cindida por vários conflitos, o principal deles o de classes, pensar a cultura significa criticar relações de poder, exclusão, dominação. No entanto, pensar em culturas escolares permite entender as diferentes formas que a dominação assume em tempos e lugares diversos. Um exemplo talvez seja a noção que alunos de zonas urbanas, os quais raramente ou nunca tiveram contato com o mundo rural, têm dos conflitos no campo. Para esses alunos, o campo pode ser um lugar idílico vendido nos mecanismos da indústria cultural, isento de problemas e "eventualmente" perturbado pela eclosão de disputas. Ora, isso nos faz reconhecer que as formas da escola se organizar em um ou em outro desses lugares de poder - o campo e a cidade - será potencialmente diferente, uma vez que aquilo que é apenas representação para alguns é experiência cotidiana para outros.

Observe-se que ao falarmos de culturas escolares, além de contrapormos a noção com diferentes outras culturas, reconhecemos que aquelas são compostas pelos alunos, mas também pelos professores, funcionários, técnicos, enfim, por todos aqueles que viabilizam o mundo da escolarização, inclusive as famílias e outros sujeitos que se enredam na vida escolar ${ }^{8}$. Por isso é pertinente a pre-

\footnotetext{
8 Um elemento aqui muito importante é a relação entre escola e família. Como lugar de crítica cultural e social radical, a escola deveria reconhecer a família como uma das instâncias da formação primeira. Mas o seu papel é, incontestavelmente, proporcionar àqueles que a freqüentam algo a mais com relação ao que a família oferece. Novamente aqui vemos a potencialidade da expressão cultura escolar: a escola não pode ser refém da família sob o risco de perder o seu sentido de pólo transmissor e produtor cultural. Ela também não pode ser refém da tradição, mas deve tratar a tradição como um dos mananciais possíveis do conhecimento.
} 
ocupação de muitos professores escolares em conhecer com mais acuidade a história de vida dos seus colegas e técnicos, além de outras pessoas da comunidade. Essa indicação é extremamente valiosa. Por meio da pesquisa com e sobre histórias de vida é possível afirmar aquilo que mudou e o que permaneceu em cada comunidade, em que medida as influências externas conformaram o mundo da escolarização e como os grupos sociais valorizam a escola. $\mathrm{Na}$ verdade, ao propormos investigar histórias de vida reconhecemos uma das dimensões fundamentais do trabalho atual dos professores: o senso de investigação, de pesquisa. Não se trata propriamente de exigir dos professores que sejam pesquisadores profissionais. A atividade de investigação exige formação longa e específica, uma preparação que pode ou não estar combinada com o magistério. No entanto, todo professor deve ter uma dimensão investigativa em sua prática pedagógica, podendo, ao problematizar a sua atuação profissional, delimitar problemáticas sobre as quais se possa pensar com mais rigor. Isso é muito importante porque não se pode intervir numa realidade sem conhecê-la e muitas vezes pensamos estar familiarizados com a nossa prática, mas, na verdade, se observarmos bem, ela nos oferece cotidianamente uma série de desafios 9 . Esse é um processo de paciência, uma vez que as mudanças no plano educativo são lentas. Isso exige, antes de tudo, uma transformação na postura por parte do professor. É preciso lembrar sempre que mudar pode gerar desconforto, uma vez que nos deparamos com o novo, com o não experimentado, com aquilo que não é esque-

9 Destaque-se que uma ferramenta muito importante desse processo é o registro escrito das atividades cotidianas. Ele pode ajudar na elaboração das problemáticas da prática pedagógica, ser objeto de análises e reflexões e ainda resguardar um pouco da memória das aulas ministradas. É claro que um professor com muitas horas diárias de ensino terá dificuldades para compor um registro de todas as suas aulas. Mas, por que não começar com algumas delas, escolhendo umas poucas turmas ou alguns dias da semana? mático. Essa é parte da riqueza da noção de culturas escolares: articular o particular e o universal, o "novo" e o "velho", o tradicional e o inovador, sem ferir as práticas e experiências de todos os envolvidos no processo de formação. Aprendendo com o passado podemos procurar ressignificar o presente e perspectivar o futuro.

Para darmos densidade às experiências e práticas, é fundamental estarmos atentos à atualização e/ou reorganização do conhecimento, tanto nos aproximando daquilo que classicamente nos é apresentado como um saber já constituído, como também refletindo e questionando sobre a construção desse saber. Assim, é importante que rompamos com a noção de que o conhecimento sempre se apresenta de forma concluída ou impenetrável ao entendimento e à ação dos agentes escolares e da própria sociedade. Em contraponto, devemos conceber o conhecimento como estando em constante construção. Isso poderá intensificar nos professores e nos alunos o desejo pelo saber, por novos entendimentos e novas produções, alargando suas possibilidades de interferência sobre o real. Considerando a relação entre cultura primeira e conhecimento elaborado, é essencial valorizarmos os saberes que compõe o cotidiano dos discentes, mas sem perder de vista a necessidade da sistematização, de tal forma que seja possível a eles transporem aquilo que já conhecem em termos corporais, ampliando seus recursos de esclarecimento e reflexão, tendo inclusive subsídios para criticar os modos de organização historicamente produzidos por nossa cultura no que tange à corporalidade, com o intuito de superá-los.

Nesse ponto destaca-se novamente o sentido que a pesquisa assume no fazer cotidiano dos professores de Educação Física de relacionar aquilo que é específico de cada comunidade com o que é universal ou pelo menos majoritário em termos corporais. Para isso é essencial que, antes de tudo, conheçamos profundamente a cultura ou as culturas 
que envolvem a nossa própria realidade. Entre outros fatores, devemos estar atentos às produções e manifestações culturais que são levadas pelos indivíduos para o interior do ambiente escolar por meio de valores, crenças, sentimentos e significados. A religião é um elemento muito lembrado pelos professores, uma vez que, muitas vezes, impede os alunos de participarem das aulas de Educação Física. Por isso é fundamental identificar os elementos centrais que compõem o cotidiano dos indivíduos para compreender como constroem determinadas formas de identidade corporal. No entanto, o papel da Educação Física deverá ser o de transcender aquilo que se apresenta como senso comum, desmistificando formas já arraigadas de entendimento sobre as práticas corporais. Desse modo deve-se priorizar a busca pelo esclarecimento como oportunidade ímpar no sentido de romper preconceitos e estereótipos. Devem merecer destaque as ações pedagógicas que intensifiquem a compreensão do aluno sobre nossa diversidade cultural em termos corporais, com o intuito de que possa tanto respeitar as diferenças identificadas, como também se posicionar frente a elas de modo autônomo, realizando opções. Como possibilidade surge a rica experiência de ampliar a comunicação entre as comunidades escolares, assim como intensificar o diálogo da comunidade escolar com outros ambientes sócio-culturais, envolvendo tanto os segmentos que o aluno costuma freqüentar como também aqueles que não conhece. Essa iniciativa pode potencializar a percepção de que a cultura, inclusive corporal, é lugar de produção de sentidos e experiências. Além disso, deve-se estimular na escola o diálogo com outras áreas de conhecimento que possam colaborar para o entendimento das manifestações corporais, tendo no horizonte as problemáticas culturais que se evidenciam em torno da corporalidade. Muitos colegas têm sugerido, nesse contexto, a necessidade de um trabalho que articule todos os agentes envolvidos no processo de escolarização, alunos, professores, funcionários e outros, com o intuito de repensar e reestruturar rituais, regras, valores, tempos e espaços que compõem o trabalho pedagógico que abrange a educação do corpo na escola. Sobre esse aspecto enfatizam a importância de reorganização de diversas práticas pedagógicas e apontam que isso só será possível por intermédio de uma interação fecunda entre os diferentes indivíduos ligados a esse trabalho. Nesse processo a Educação Física teria uma importância fundamental justamente por apresentar como centro de interesse as práticas corporais.

Assim, baseados nessas expectativas e na experiência dos professores, na noção de corporalidade e nas finalidades que regem a escolarização pública, propomos a articulação do trabalho docente em torno de alguns eixos. Eles não são conteúdos, mas orientações, pilares de igual importância, mas que ganham maior ou menor presença de acordo com o contexto - o espaço e o tempo - onde a Educação Física se apresenta. São eles:

- o corpo que brinca e aprende: manifestações lúdicas;

- potencial expressivo do corpo;

- desenvolvimento corporal e construção da saúde;

- relação do corpo com o mundo do trabalho;

Esses eixos, muito mais do que simples temáticas, devem significar o apoio necessário à organização do trabalho do professor, uma base sobre a qual a sua ação poderá ser estruturada. Deles poderão emergir aqueles elementos da cultura que constituirão os temas de ensino, conforme as finalidades, os objetivos e os pressupostos dos docentes. Sobre eles é possível uma palavra.

O eixo caracterizado como o corpo que brinca: manifestações lúdicas ganha relevância quando entendemos que por intermédio do brincar o indivíduo é capaz de estabe- 
lecer conexões entre o imaginário e o real, refletindo sobre os lugares sociais assumidos nas relações estabelecidas em grupo ${ }^{10}$. Desse modo, é possível, entre outras ações, questionarmos as diferentes formas de poder exercidas por meio da corporalidade, as situações de exclusão geradas de acordo com as características apresentadas pelos indivíduos, estejam elas ligadas à raça, à etnia, ao gênero, à classe social, marcas distintivas de diferentes possibilidades da construção do brincar. É notável o número de situações que podem emergir durante a construção de brinquedos ou na participação em brincadeiras, sejam elas estimuladas pelo professor ou geradas de forma espontânea pelos alunos. Ganham destaque a construção individual ou coletiva de brincadeiras, os materiais (lembremos que o corpo é o primeiro brinquedo das crianças), as diferenças, continuidades e descontinuidades entre jogo e esporte, o caráter tradicional ou contemporâneo dos brinquedos e brincadeiras etc.

Essas situações podem, no entanto, propiciar tanto a potencialização quanto à interdição das formas de expressão do corpo. Aqui poderíamos exemplificar com a importância do contato corporal e o necessário respeito mútuo que este reclama; do grupo estabelecer critérios que contemplem todos os participantes; do respeito por aqueles que de alguma forma não conseguem realizar o que foi proposto pelo próprio grupo, colocando em jogo as expectativas. No entanto, na escola é fundamental que ao brincar as situações sejam problematizadas por meio de uma reflexão apurada, com elementos que levem o indiví-

10 Segundo Vaz, Peters e Losso (2002), “(...) as brincadeiras são expressões miméticas privilegiadas na infância, momentos organizados nos quais o mundo, tal qual as crianças o compreendem, é reelaborado, contestado, dramatizado, experienciado. Nelas as crianças podem viver, com menos riscos e interpretando atuando de diferentes formas, as situações que lhes envolvem o cotidiano. Desempenham um papel e logo depois outro, seguindo, mas também reconfigurando, regras. São momentos de representação e apresentação, de apropriação do mundo". duo a questionar formas já "naturalizadas" de preconceito, domesticação e violência sobre o corpo. Assim, pretende-se que os indivíduos tenham condições tanto de entender e respeitar o diferente, como também de posicionarem-se frente ao mundo. Por esse ângulo, torna-se interessante o reconhecimento das formas particulares que o brinquedo e a brincadeira tomam em distintos contextos e momentos históricos, por variadas comunidades e grupos. A pluralidade de possibilidades pode ampliar a percepção e a interpretação diferenciadas da realidade, intensificando a curiosidade, o interesse e a intervenção daqueles que estão envolvidos na realização de diferentes brincadeiras.

Além disso, é bom reconhecer que o brincar pode representar uma atitude espontânea, de fruição, que atua como possibilidade de construção da autonomia, uma das finalidades básicas do processo de escolarização. Quando brincamos aprendemos a nos mover entre a liberdade e os limites, os nossos e os estabelecidos pelo grupo no qual nos inserimos.

O segundo eixo proposto, caracterizado como potencial expressivo do corpo, deve permitir que o professor escolar aborde as manifestações corporais a partir de diferentes possibilidades de expressão. Observando que corporalmente expressamos alegria, dor, preconceito, prazer, raiva, medo etc., as manifestações corporais podem ser um índice para uma prática escolar voltada para a busca da autonomia a partir do reconhecimento consciente dos limites e das possibilidades corporais dos indivíduos. Esses limites e essas possibilidades devem permitir a interação, o conhecimento, a partilha de experiências que viabilizem a reflexão, a inserção crítica no mundo e o desenvolvimento de um sentimento de alteridade, entendida como reconhecimento do que é distinto. Aqui podemos lembrar das várias formas expressivas no circo, na dança, nos malabares, na ginástica, no esporte e no teatro, em outras atividades rítmico-expressivas, de imitação/representa- 
ção, mas também de experiências corporais como a dor, o prazer, o reconhecimento dos limites, as privações, a educação dos sentidos (cheiros, gostos, sons, imagens, senso tátil), a identificação daquilo que nosso corpo produz ao relacionar-se com o meio. Cada uma destas manifestações culturais nos reserva diferentes formas de comunicação por meio da corporalidade, o que implica reconhecer suas inúmeras possibilidades de representação e significação.

O terceiro eixo, desenvolvimento corporal e construção da saúde, permite entender a vida saudável como uma construção que supõe uma dimensão histórico-social. Portanto, contrária à tendência dominante de conceber a saúde como mera volição individual, o eixo deve oferecer elementos para o entendimento da articulação entre individual e cultural. Os indivíduos - docentes e discentes - podem construir uma vida saudável desde que as condições objetivas para tanto sejam oferecidas pela sociedade, o que confere ao tema uma dimensão política. Ou seja, a saúde é um bem que pode ser alcançado pela boa alimentação, saneamento básico, boas condições de moradia, educação e informação, preservação do meio ambiente, acesso aos equipamentos de lazer, enfim, pelo direito às condições mínimas para uma vida digna. No horizonte dessas preocupações estão a atividade física moderada e o acesso ao sistema formal de atendimento à saúde. Trata-se, pois, de superar uma ênfase histórica, que permanece atual, sobre a saúde como algo "natural" ou que se adquire pela dor, pelo sacrifício, apenas pelo esforço individual. A saúde não é uma dádiva concedida a alguns, mas um processo constante de conquista, algo a ser construído coletivamente e que exige boas condições de vida. A "falta de saúde" não pode, portanto, ser atribuída como culpa individualizada, mas deve ser compreendia no contexto da vida social do indivíduo. Nesse sentido, podemos abordar o uso de substâncias entorpecentes e os seus efeitos sobre a saúde, mostrando o que motiva a produção e a disseminação dessas substâncias, o tráfico de drogas etc. Outro exemplo seria a busca pelas atuais formas de tratamento, modelação, intervenção sobre o corpo com o intuito de alcançar, a qualquer custo, os modelos instituídos de beleza e a "saúde perfeita". Podemos ainda pensar na sexualidade com duplo significado: um que a entende como possibilidade de fruição, prazer, alegria, encontro; outro que a compreende naquilo que ela representa da miséria humana: prostituição infantil, dominação sexual, sexismo, violência, DSTs etc.

Esse eixo nos ajuda a pensar o corpo como um cruzamento entre a natureza e a cultura. Nesse encontro culminam os preconceitos e tabus relacionados ao corpo (lembremos que nas aulas de Educação Física o corpo está muito exposto), os muitos vetores que conformam nossa corporalidade (gênero, etnia, classe social, pobreza, religião, migrações etc.), as adjetivações que os corpos ganham (limpo/sujo, feio/ bonito, forte/fraco, magro/gordo, saudável/ doente, livre/aprisionado, masculino/feminino, jovem/velho etc.), o caráter de suporte do corpo (moda, adereços, consumo etc.), a relação entre corpo e meio ambiente. Esses, entre muitos outros aspectos, podem ser potencializados por este eixo, sempre que ele seja visto em conjunto com toda a proposta das diretrizes.

Portanto, ao compararmos tal perspectiva com uma das mais tradicionais orientações do ensino de Educação Física, aquela que concebe esta disciplina como um tempo e um espaço que devem intervir sobre a aptidão física dos educandos, devemos ter em conta que a escola é um lugar onde se deve refletir sobre práticas e discursos que ensinem cuidados com a saúde como investimento também individual. No entanto, não é possível deixar de contemplar elementos sociais, culturais, políticos e econômicos que interferem na possibilidade de construção social da saúde para todos.

Nesse quadro podemos destacar ainda a questão da inclusão de pessoas com histórico de deficiência nas aulas de Educação Física. 
Muito do discurso hegemônico da área insiste na idéia de que a Educação Física e a prática esportiva melhoram a saúde. Isso pode ser verdade. Mas, por que, então, excluir aqueles que consideramos deficientes? De forma geral, não temos boas respostas para a inclusão, especialmente na Educação Física, onde a regra da eficiência vigora. Se não formos capazes de romper com a determinação do modelo esportivizante e seus códigos (vitória-derrota, ênfase na técnica e no desempenho máximo, comparações absolutas e objetivas etc.), não haverá como ter inclusão. Destaque-se que esta não pode ser encarada como "caridade" ou assistencialismo, mas como possibilidade de afirmação da pluralidade, da diferença, do aprendizado com o outro, algo que todos os alunos devem ter como experiência formativa ${ }^{11}$.

O quarto eixo, relação do corpo com o mundo do trabalho, pretende dar conta da exposição do corpo ao sacrifício do trabalho. O Brasil - e o Paraná não está imune a tais problemas - é um país com altíssimos índices de desemprego; além disso, a maior parte daqueles que estão empregados têm renda incompatível com as suas necessidades básicas. Esses aspectos contribuem de forma direta para lançar uma boa parte da sua população a condições indignas de vida, seja nas zonas rurais ou urbanas. Só por esse aspecto - a exclusão - o trabalho deveria ter lugar nos nossos currículos. Além disso, há uma dimensão do trabalho, freqüentemente negligenciada pelos educadores, com a qual nos deparamos cotidianamente nas nossas escolas. Trata-se

11 Ainda no plano da afirmação das diferenças, lembremos a necessidade de valorização das experiências corporais do campo e dos povos indígenas. Esses registros culturais têm riquíssimos acervos vinculados à corporalidade que freqüentemente são esquecidos em nome do predomínio dos modelos hegemônicos de educação do corpo do universo urbano. Não se trata, portanto, de apenas levar as práticas corporais para as escolas rurais e indígenas - o que deve ser feito mas, também, dialogar com esses universos no sentido da ampliação do horizonte de possibilidades corporais de todos os alunos, inclusive propiciando aos da cidade que aprendam com as culturas que lhes são, em princípio, distantes. do trabalho infantil, da prostituição, da escravidão e de tantas outras formas possíveis de perpetuar as relações de dominação pela via do trabalho. Devemos notar o quanto essas formas recorrem ao corpo para manter-se atualizadas, ou o quanto o corpo assimila e expressa essas marcas de dominação pelo trabalho. Meninas e meninos que são levados à prostituição aos 10,12 anos de idade, ou ainda mais jovens, fornecendo ampla oferta para um mercado, inclusive da pornografia; os pequenos trabalhadores do campo ou da cidade, muitas vezes nossos alunos, submetidos a longas horas de trabalho que os impedem de fruir a vida como pessoas em desenvolvimento - os exemplos que podemos tirar das carvoarias, das plantações de sisal, das olarias, tanto quanto das ruas das cidades, na coleta de lixo, na construção civil etc., mostram o quanto a exploração do homem inicia-se pelo esgotamento coercitivo das suas possibilidades corporais. Podemos ver também essas manifestações naqueles indivíduos que reviram lixo para comer e manterem-se vivos. Entre outros aspectos vale ressaltar as diferentes frentes de trabalho existentes do Estado do Paraná (apontadas pelos professores no decorrer de discussões para estas diretrizes) que dispõem da força de trabalho de crianças e adolescentes das nossas escolas, tais como o trabalho doméstico, o agrícola, entre outros. Isso sem esquecermos a falta de trabalho que afeta as famílias de muitos dos nossos alunos. Embora muitos possam objetar que o trabalho não é um fato identificado de modo constante no ensino fundamental, é preciso reconhecer que todos os indivíduos, direta ou indiretamente, independente da sua faixa etária, sofrem as conseqüências advindas de uma sociedade estruturada fundamentalmente em torno das relações de trabalho assalariado.

Se articularmos a saúde com o trabalho, dois dos eixos aqui apontados, somos levados a perguntar como podemos atualizar um discurso escolar sobre a saúde quando parte significativa da nossa população alimenta-se do 
que encontra no lixo das nossas cidades, nos nossos restos. Ainda que possamos tratar tais situações como extremas - mas lembremos que elas são comuns e recorrentes - teríamos o exemplo mesmo daqueles trabalhadores ditos "regulares". Esses se submetem a cargas de trabalho absurdas, dia após dia, com pouquíssimo tempo para viver outra vida que não seja em função do trabalho. $\mathrm{O}$ trabalhador que acorda com o dia ainda escuro, trabalha 10 ou 12 horas por dia, freqüentemente de uma forma extenuante que o brutaliza, e que recebe salários incompatíveis com as suas necessidades mais básicas, como é possível que ele tenha saúde, alegria, felicidade, enfim, dignidade? $\mathrm{E}$ onde, senão no corpo, se expressam todas as marcas dessa penúria, desse sacrifício? Seria por outro motivo a grande onda da ginástica laboral de algumas décadas para cá? O que significa essa forma de atividade corporal a não ser o aumento da capacidade dos indivíduos para suportar as penúrias do trabalho? Além disso, esses indivíduos, pela própria exposição permanente à exploração do trabalho, que tempo teriam para dedicar-se à família, aos seus interesses próprios (e não do trabalho)? Ou seja, o lazer, tema importante da Educação Física, precisa ser entendido hoje como quase uma impossibilidade para a maior parte dos indivíduos. Não é por outro motivo que se desenvolve toda uma indústria do entretenimento que tem como função primeira justamente recuperar as energias do trabalhador para que suporte a rotina destruidora da fábrica, da roça, do escritório e da escola. Isso nos faz pensar se a baixa qualidade da "produção cultural" que é disseminada pelos meios de comunicação não representa justamente essa lógica de oferecer algo aos indivíduos que os faça acreditar na possibilidade de atenuação dos efeitos do trabalho. Ora, é do corpo, é da corporalidade que estamos tratando. Quantos de nossos alunos, nos mais diversos lugares do Brasil e do Paraná conseguiram escapar ou subverter essa lógica? E mais, como aquele professor que trabalha 40 ou 60 horas, muitas vezes em diferentes empregos, com um salário indigno, com condições por vezes adversas: como estes professores se "enxergam" na experiência universal do trabalho como sacrifício e dominação, penúria e dor? Lembremos que o trabalho pode ser entendido como necessidade humana, como relação necessária com a natureza, enfim, como condição de humanização. No entanto, a forma que adquire na sociedade capitalista acaba tornando-o sinônimo de opressão e exploração. Nesse sentido, não se pode dizer que ele redime, liberta, realiza e dignifica, mas, sim, que ele é expressão da violência contra o corpo, momento que não dignifica a humanidade.

Se as manifestações corporais são possibilidades, podemos pensar na escola como lugar de busca de alternativas à reificação do corpo? Para além da crítica, da qual nunca devemos abrir mão, a escola pode representar também um lugar de contraponto. Um espaço onde os indivíduos possam refletir e perceber como a sociedade se organiza em função de escolhas mais ou menos conscientes de indivíduos e grupos.

Por fim, ao propormos essas questões, temos o intuito de demonstrar como o alargamento da compreensão das práticas corporais na escola pode representar uma reorientação nas maneiras de concebermos o papel da Educação Física na formação. Isso significa identificarmos as múltiplas possibilidades de intervenção sobre a corporalidade que surgem no cotidiano de cada cultura escolar na sua especificidade. Para isso o trabalho docente deve ser balizado por uma intencionalidade que pretenda repensar o papel do professor e da Educação Física ao longo da escolarização na tentativa de desmistificar formas "naturalizadas" de compreensão da sua função social. Trata-se, entre outras coisas, de desfazer algumas representações que consideram professores e alunos de Educação Física como atletas, portadores de saúde perfeita, exímios praticantes de diversas formas de atividade física etc.

Vários dos professores escolares ressaltaram a figura do professor como elemento cen- 
tral nesse processo de reestruturação da Educação Física na escola. Apesar de reconhecerem que isso exigirá um intenso esforço, foi salientado que o professor precisa, necessariamente, ter clareza quanto à intenção de seu trabalho ao longo do processo de escolarização, com o intuito de realmente contribuir para a formação humana. Antes de tudo, é fundamental que os professores reflitam sobre sua própria corporalidade, revendo posicionamentos à luz da cultura elaborada, desconstruindo mitos e tradições inventadas. Afora isso, também é importante que o professor compreenda que a cultura escolar pode ser a marca de experiências dolorosas para crianças e jovens cujas histórias são pontilhadas por recusas, exclusões, discriminações e carências do ponto de vista corporal. Portanto, faz parte de um desafio permanente do professor procurar produzir uma cultura escolar de Educação Física que mobilize práticas que afirmem valores e sentidos que ampliem as possibilidades formativas, evitando formas de discriminação, segregação e competição exacerbada. É tarefa do professor mediar situações conflitantes que envolvam a corporalidade por meio do diálogo e da reflexão, dispondo de argumentos que favoreçam o esclarecimento dos sujeitos envolvidos no processo educativo. Nesse sentido, ele necessita refletir sobre a cultura que interfere sobre nossa corporalidade, com vistas a não somente reproduzi-la. Do mesmo modo, precisa colocar-se no papel de articulador do conhecimento e não se posicionar como o detentor de uma verdade dada e acabada. Isso poderá ocorrer na medida em que o professor contemple em seu trabalho saberes que oportunizem uma maior reflexão dos alunos sobre o corpo, reconhecendo e atribuindo a ele sentidos éticos e estéticos, inspirando experiências que possam ser de fato formativas, não as restringindo à prática de movimentos empobrecidos em seus significados. Logo, é fundamental que ele esteja atento às peculiaridades que envolvem a corporalidade no mundo contemporâneo, tomando como referência aquilo que se apresenta como o que há de mais relevante em termos de conhecimento e produção cultural. Ele não pode resumir a educação do corpo à prática de atividades físicas descontextualizadas, mas entendê-las como uma dimensão complexa e abrangente. Isso poderá viabilizar-se na medida em que os alunos explorem sua corporalidade por meio de atividades e experiências orientadas pelo professor que, por sua vez, deverá ter como premissa a elaboração de um planejamento que considere as diversas manifestações corporais presentes no meio escolar, indo além dos conteúdos ditos tradicionais, oportunizando a todos experiências de fato significativas para a formação.

\section{On corporality and schooling: contributions to the reorientation of school practices in physical education}

\begin{abstract}
This paper intends to contribute to the debate on syllabus design guidelines for the teaching of Physical Education in the state of Paraná, Brazil. After presenting the context in which this paper was generated - which includes the results of debates among schools teachers from that state - it discusses a conception for Physical Education as a school subject, a pedagogical space in which the education of the body is at the forefront. As such, a series of concepts and arguments are presented in favor of corporality as the core stimulator of physical education classes which, in turn, can be organized around four axes: the body which plays and learns; the body's expression potential; body development and the construction of health; the relationship between the body and the world of work. In alignment with the concept of corporality here presented, we argue in favor of a broadening of the understanding of body practices which consider elements beyond body movement.

Keywords: Corporality - Education of the Body School Physical Education - Syllabus Guidelines Paraná
\end{abstract}

Sobre corporalidad y escolarización: contribuciones para la reorientación de las practicas escolares de la disciplina educación física

\section{Resumen}

Este artículo reúne contribuciones al debate sobre la constitución de directrices curriculares para la enseñanza de Educación Física en el estado de Paraná, Brasil. Después de presentado el contexto en lo cual se generó 
el texto - que incluye resultados de debates con profesores escolares de aquel estado - se discute una concepción para la disciplina Educación Física en la escuela, espacio pedagógico en el cual la educación del cuerpo es protagonista. Se presenta entonces una serie de conceptos y argumentos a favor de la corporalidad como centro articulador de las clases de Educación Física que, a su vez, pueden ser organizadas alrededor de cuatro ejes: el cuerpo que juega y aprende, potencial expresivo del cuerpo, desarrollo corporal y construcción de la salud, relación del cuerpo con el mundo del trabajo. Se argumenta, en correspondencia con el concepto de corporalidad presentado, por una comprensión más ancha de las prácticas corporales que considere elementos más allá del movimiento corporal.

Palabras-clave: Corporalidad - Educación del Cuerpo - Educación Física Escolar - Diretrizes Curriculares Paraná

\section{Referências}

PRADO, P. D.; DEMARTINI, Z. B.; FARIA, A. L. G. (Org.). Por uma cultura da infância: metodologias de pesquisa com crianças. Campinas: Autores associados, 2002. 153 p.

COLETIVO DE AUTORES. Metodologia de ensino de Educação Física. São Paulo: Cortez, 1992.

KUNZ, E. Educação Física: ensino e mudanças. Ijuí: EDUNIJUÍ, 1991.

OLIVEIRA, L. P. A, e TABORDA DE OLIVEIRA M. A. Corporalidade, trabalho e técnica: reflexões a partir da filosofia da história de Herbert Marcuse. Anais do XIV Congresso Brasileiro de Ciências do Esporte: Ciência para a vida. Porto Alegre: CBCE, 2005.

SAYÃO, D. T. Corpo e movimento: notas para problematizar algumas questões relacionadas à educação infantil e à educação física. Revista Brasileira de Ciências do Esporte, Campinas, v. 23, n. 2, p. 55-68, 2002.

TABORDA DE OLIVEIRA, M. A. Existe espaço para o ensino de Educação Física na escola básica? Pensar a Prática. Goiânia, 2: 1-23, jun./jul. 1998.
TABORDA DE OLIVEIRA M. A.; OLIVEIRA, L. P. A. de. Corporalidade e cultura escolar: refletindo sobre a reorientação das práticas escolares de Educação Física no Estado do Paraná. Curitiba: Secretaria de Estado da Educação do Paraná, 2004.

TREBELS, A. H. Uma concepção dialógica e uma teoria para o movimento humano. $R e-$ vista Perspectiva. Florianópolis, v. 21, n. 1, p. 249-267, 2003.

VAGO, T. M. Início e fim do século XX: maneiras de fazer educação física. Cadernos CEDES. Campinas, n. 48, p. 30-51, 1999.

VAZ, A. F.; PETERS, L. L.; LOSSO, C. D. Identidade cultural e infância em uma experiência curricular integrada a partir do resgate das brincadeiras açorianas. Revista de Educação Física/UEM. Maringá, v. 13, n. 1, p. 7177, 2002.

\section{Agradecimento}

Agradecemos à equipe do ensino fundamental da Secretaria de Estado da Educação do Paraná, formada por Cíntia Muller Angulski, Claúdia Sueli Litz Fugikawa, Liane Inês Pereira e Marcelo Ciola da Costa pelo convite, pela acolhida e pelas discussões que fizeram aperfeiçoar nossas contribuições. Da mesma forma, nosso muito obrigado aos professores escolares que debateram as idéias e nos exigiram torna-las melhores no alcance e na precisão. Nem todas as lacunas foram preenchidas e os deslizes que ainda sobraram devem ser creditados exclusivamente aos autores desse texto. Esse texto foi e está sendo publicado, em versões modificadas, em documentos da Secretaria que tratam das diretrizes curriculares do Estado do Paraná.

Recebido em: 16/07/2008

Revisado em: 19/11/2008

Aprovado em: 26/08/2008

Endereço para correspondência

alexfvaz@pq.cnpq.br. 